\title{
A short-term follow-up comparison of two trans-obturator tape procedures
}

\author{
Menahem Neuman • Boris Friedman • Avi Stein • \\ A. Ami Sidi • Alexander Tsivian
}

Received: 9 June 2006 / Accepted: 5 April 2007 / Published online: 10 July 2007

(C) Springer-Verlag 2007

\begin{abstract}
The objective of the study was to compare the clinical outcomes at the short-term follow-ups of two novel transobturator mid-urethral sling procedures - the transobturator tape (TOT) procedure and the tension-free vaginal tape (TVT)-obturator procedure. The study cohort consisted two groups of 40 women with urodynamically proven stress urinary incontinence (SUI). The patients in one group underwent the TOT procedure, performed according to Delorme (Prog Urol 11:1306-1313, 2001); those in the second group underwent the TVT-obturator operation, performed according to de Leval (Eur Urol 44:724-730, 2003). Intra-operative diagnostic cystoscopy was not performed with either the TVT-obturator or the TOT procedures. The average follow-up was 12 months. The two patient groups were similar in terms of demographic and therapeutic criteria, except for patient age, which was significantly younger in the TVT-obturator group. Previously reported TVT-related operative complications, such
\end{abstract}

\section{Neuman ( $\square)$}

Department of Obstetrics and Gynecology,

Shaare-Zedek Medical Center,

P.O.B. 3235, Jerusalem 91031, Israel

e-mail: neuman@szmc.org.il

\section{Neuman}

The Ben-Gurion University of the Negev,

Beer Sheba, Israel

B. Friedman · A. Stein · A. A. Sidi

Department of Urology, Carmel Medical Center,

Haifa, Israel

A. Tsivian

Department of Urologic Surgery, The E. Wolfson Medical Center, Holon and Sackler School of Medicine, Tel Aviv University,

Tel Aviv, Israel as bladder penetration, intra-operative bleeding, field infection and post-operative pelvic floor relaxation, were not observed in patients of either group. Bowel and urethral injuries were also not recorded. The therapeutic failure rates were $10 \%$ for the TOT procedure and $5 \%$ for the TVTobturator procedure. Urinary frequency and urgency postoperatively were reported in $25 \%$ of the TOT patients and $19 \%$ of the TVT-obturator patients, pelvic or vaginal pain affected $10 \%$ of the TOT and $5 \%$ of the TVT-obturator patients, while post-operative voiding difficulty was experienced by $12.5 \%$ of the TOT and $7.5 \%$ of the TVTobturator patients. None of the above-mentioned differences between the two patient groups were of statistical significance. The TVT-obturator and TOT procedures, both minimally invasive, novel, mid-urethral sling procedures, seem to be safe, easy-to-perform and effective in treating female SUI. The patients of both study groups suffered less intra- and post-operative surgical complications than previously been reported in connection with the TVT operation. The TVT-obturator patients had fewer therapeutic failures, less post-operative urinary frequency and urgency, less pelvic pain and less voiding difficulty. All of these findings, however, had no statistical significance; consequently, longterm comparative data collection will be required before solid conclusions can be drawn on the superiority of either of these two operative techniques.

Keywords Trans-obturator tape · USI

\section{Introduction}

The tension-free vaginal tape (TVT) procedure, first described by Ulmsten et al. in 1996 and based on midurethral prolene tape support, is a surgical procedure used 
for treating female stress urinary incontinence (SUI) [1-6]. Although the procedure is well-established, a number of complications are associated with the TVT operative approach that have drawn the concern of surgeons. These include bladder penetration $[2,3,6]$ and post-operative urinary outlet obstruction $[2,3,6,8,10]$ as well as bowel penetration, intra-operative bleeding, and post-operative infection [2, 3, 6-9]. The latter three complications entail the potential risk of severely harming the health of the patient. Against this background, de Leval [11] and Delorme [12] designed novel transobturator mid-urethral sling procedures. Jean de Leval described the TVTobturator as follows: "while the TVT needle passes through the retropubic area, which is proximal to the neighboring bladder, bowel and blood vessels, the newly reported TVTObturator needle route runs through the relatively safe medial compartment of the obturator fossa area" [11]. Delorme developed the transobturator tape (TOT) procedure, in which a skin incision is made at the genitofemoral fold at the level of the clitoris and the tape is inserted through the obturator foramen underneath the urethra. The vaginal wall is then re-approximated with a running Vicryl $2 / 0$ suture [12].

This study reported here was designed to compare surgeons' learning curves for these two TOT procedures.

\section{Methods}

Patients suffering from SUI, diagnosed both clinically and urodynamically, were referred for corrective surgery. The first author performed the TVT-obturator procedures, and the last author performed the TOT procedures. The second and third authors compared the patients' series for these two different types of procedures. Data were collected by telephone interview based on the Urinary Distress Index (UDI)-6 validated questionnaire. The TVT-obturator operations were carried out according to de Leval [11] and the TOT procedure was according to Delorme [12]. All of the operated patients were given $1 \mathrm{~g}$ Monocef (Cefonicid; Beecham Healthcare) intravenously $1 \mathrm{~h}$ prior to surgery [13] and had an iodine antiseptic prophylactic vaginal wash before commencement of surgery. The mode of anesthesia depended on the patient's request. Diagnostic cystoscopy was not carried out in either patient group. Therapeutic failures were confirmed by repeat urodynamic studies and treated successfully by TVT. Patients with early postoperative partial outlet obstruction were treated with bladder catheterization for up to 2 weeks [8]. All statistical analyses were performed with SPSS ver.10.1.4 (SPSS, Chicago, Ill.). The $t$-test was used for quantitative variance analysis, while the Fisher's exact test and the chi-square test were used for categorical variance. All statistical tests were evaluated at the $P=0.05$ level of significance.

\section{Results}

The demographic and operative data of the patients in both study groups are presented in Table 1. Patients presenting with other significant features of pelvic floor relaxation had anterior and posterior colporrhaphy or vaginal hysterectomies concomitant with the anti-incontinence surgery. No statistically significant differences in demographic and operative data were found when comparing those two groups, with the exception that the patients in TVTobturator groups were younger (average: 52 vs. 62 years). The patients were followed-up for an average period of 12 months (range: 5-19 months). Previously reported TVTrelated operative complications, such as bladder penetration,

Table 1 Patient demographics (NS not significant)

\begin{tabular}{llll}
\hline & TOT group & TVT- obturator group & Statistical significance $(P$ value $)$ \\
\hline Age (years; average and range) & 62.5 & 52.8 & 0.001 \\
Previous anti-incontinence surgery $(n$ and $\%)$ & $4(10 \%)$ & $1(2.5 \%)$ & $0.36(\mathrm{NS})$ \\
Previous hysterectomy $(n$ and $\%)$ & $4(10 \%)$ & $2(5 \%)$ & 0.396 (NS) \\
Cystocele grade 2 and 3 & 19 & 18 & 0.81 (NS) \\
Rectocele grade 2 and 3 & 4 & 6 & 0.45 (NS) \\
Additional operations (No. and \%) & $21(52.5 \%)$ & $22(55 \%)$ & 0.823 (NS) \\
A. Colporrhaphy & 17 & 15 & \\
P. Colporrhaphy & 2 & 3 & 0.356 (NS) \\
A. and P. Colporrhaphy & 2 & 1 & $13(32.5 \%)$ \\
Vaginal hysterectomy & $17(42.5 \%)$ & & \\
Background diseases & a $(n$ and $\%)$ & &
\end{tabular}

TOT, Transobturator tape; TVT-obturator, tension-free vaginal tape-obturator

a Bronchial asthma, hypertension, diabetes, among others 
intra-operative bleeding, field infection, and post-operative pelvic floor relaxation, were not noted any patients; bowel and urethral injuries were also not recorded. Post-operative complications within these two patient series were recorded and are presented in Table 2. Tape loosening or removal was not required. The therapeutic failure rates were $10 \%$ for the TOT and 5\% for the TVT-obturator. Urinary frequency and urgency post-operatively was reported in $25 \%$ of the TOT and $19 \%$ of the TVT-obturator patients, pelvic or vaginal pain affected $10 \%$ of the TOT and $5 \%$ of the TVT-obturator patients, and post-operative voiding difficulty was experienced by $12.5 \%$ of the TOT and $7.5 \%$ of the TVT-obturator patients. None of these differences between the two patient groups were statistically significant.

\section{Discussion}

Since being described by Ulmsten et al. in 1996 [1], the TVT procedure has become very popular. Common complications of former operations for the treatment of SUI, such as intraoperative blood loss, pelvic and abdominal organ injury, post-operative de-novo Detrusor instability, dyspareunia, and urethral erosion, are rare in the TVT era [1-5]. Prospective randomized multi-center studies that have compared TVT and the former gold standard, the Burch colposuspension, have demonstrated a similar therapeutic impact for both. However, TVT had a higher intra-operative complication rate, while colposuspension had a higher post-operative complication rate and a longer recovery period [14-19]. Among the well-documented typical TVT complications are bladder penetration, intra-operative bleeding, post-operative field infection, and bowel injury [1-3, 5]. De Leval [11] and Delorme [12] described novel TVT-related procedures that enable mid-urethral support for the treatment of female SUI without coming into the vicinity of the bladder, the femoral blood vessels, or the bowel. This is achieved by using the obturator fossa, rather than the retropubic space, as a route for the prolene tape. The results of our comparative study are in line with the previously reported efficacy of the TOT and the TVT-obturator procedures in terms of cure and early and late post-operative complication rates [20]. The short-term results for TOT and TVT-obturator surgery include fewer cases of bladder penetration, intra-operative bleeding, and post-operative field infection in comparison to the TVT approach. The therapeutic failure rates, post-operative urinary frequency and urgency, pelvic or vaginal pain, and voiding difficulty that our patients encountered were all slightly more common in patients who underwent the TOT procedure than in those having the TVT-obturator procedure, but those findings had no statistical significance. None of these differences between the two patient groups were of statistical significance. This lack of significant difference between the outcome measures of the two patient groups may be partially due to the relatively short follow-up period for the recently launched TOT and TVT-obturator procedures as well as to the accumulated surgical experience with midurethral sling placement following the learning curve period for TVT. However, our study was a short-term one with a subjective nature. A long-term follow-up for objectively measured large-scale studies will be required before solid conclusions can be drawn with regard to advocating TOT placement as the procedure of choice for the treatment of female SUI.

\section{Conclusion}

The TOT and TVT-obturator procedures, two novel midurethral sling operations for the treatment of female SUI, seem to be effective, easy-to-learn, and safe procedures. Intra-operative diagnostic cystoscopy for ruling out bladder
Table 2 Post-operative variables (NS not significant)

\footnotetext{
according to the International Classification for Standards (ICS) committee guidelines
}

\begin{tabular}{|c|c|c|c|}
\hline $\begin{array}{l}\text { Post-operative } \\
\text { variables }\end{array}$ & $\begin{array}{l}\text { TOT group } \\
(n=40)\end{array}$ & $\begin{array}{l}\text { TVT-obturator group } \\
(n=40)\end{array}$ & $\begin{array}{l}\text { Statistical significance } \\
(P \text { value })\end{array}$ \\
\hline Urgency $^{a}$ & $9(25 \%)$ & $7(19.4 \%)$ & $0.153(\mathrm{NS})$ \\
\hline Frequency $^{\mathrm{a}}$ & $9(25 \%)$ & $7(19.4 \%)$ & $0.428(\mathrm{NS})$ \\
\hline UDI-6 (Pts/level) & $5 / 3,2 / 2,2 / 1$ & $4 / 3,3 / 2$ & \\
\hline Urge incontinence $^{\mathrm{a}}$ & $2(5 \%)$ & $3(7.5 \%)$ & O.778 (NS) \\
\hline UDI-6 (Pts / level) & $6 / 3,3 / 2$ & $5 / 3,2 / 2$ & \\
\hline Stress incontinence ${ }^{a}$ & $4(10 \%)$ & $2(5 \%)$ & $0.115(\mathrm{NS})$ \\
\hline UDI-6 (Pts/level) & $3 / 1,1 / 2$ & $1 / 3,1 / 2$ & \\
\hline Voiding difficulty $^{a}$ & $5(12.5 \%)$ & $3(7.5 \%)$ & $0.891(\mathrm{NS})$ \\
\hline UDI-6 (Pts/level) & $3 / 3,2 / 2$ & $2 / 3,1 / 2$ & \\
\hline Pelvic pain & $2(5 \%)$ & $0(0 \%)$ & NS \\
\hline UDI-6 (Pts/level) & $1 / 3,1 / 2$ & & $0.262(\mathrm{NS})$ \\
\hline Vaginal pain & $2(5 \%)$ & $2(5 \%)$ & $0.494(\mathrm{NS})$ \\
\hline
\end{tabular}


penetration is not required with these surgical approaches. The short-term follow-up results of the present study for TOT and TVT-obturator are comparable: both the TOT and TVT-obturator procedures resulted in fewer intra-operative and post-operative complications than the TVT. Further follow-up is required for the transobturator operation before it can be recommended as primary care of female SUI.

\section{References}

1. Ulmsten U, Henriksson L, Johnson P, Varhos G (1996) An ambulatory surgical procedure under local anesthesia for treatment of female urinary incontinence. Int Urogynecol J 7:81-86

2. Olsson I, Kroon U (1999) A three-year post-operative evaluation of tension-free vaginal tape. Gynecol Obstet Invest 48:267-269

3. Kuuva N, Nilsson CG (2002) A nationwide analysis of complications associated with the tension-free vaginal tape (TVT) procedure. Acta Obstet Gynecol Scand 81:72-77

4. Paraiso MFR, Muir TW, Sokol AI (2002) Are mid-urethral slings the gold standard surgical treatment for primary genuine stress incontinence? J Am Assoc Gynecol Laparosc 9:405-407

5. Groutz A, Gordon D, Wolman I, Jaffa AJ, David MP, Lessing JB (2002) Tension-free vaginal tape for stress urinary incontinence: Is there a learning curve? Neurol Urodynam 21:470-472

6. Waetjen LE, Subak LL, Shen $\mathrm{H}$ et al (2003) Stress urinary incontinence surgery in the United States. Obstet Gynecol 101:671-676

7. Neuman M (2003) Low incidence of post-TVT genital prolapse. Int Urogynecol J 14:191-192

8. Neuman M (2004) Post tension-free vaginal tape voiding difficulty - prevention and management. J Pelvic Med Surg 10:19-21
9. Neuman M (2004) Transvaginal tape readjustment after unsuccessful tension-free vaginal tape operation. Neurourol Urodynam 23:282-283

10. Neuman M (2002) Infected hematoma following tension-free vaginal tape implantation. J Urol 168:2549

11. De Leval J (2003) Novel surgical technique for the treatment of female stress urinary incontinence: Transobturator vaginal tape inside-out. Eur Urol 44:724-730

12. Delorme E (2001) Transobturator urethral suspension: a minimally invasive procedure to treat female stress urinary incontinence. Prog Urol 11:1306-1313

13. Neuman M (2007) Prophylactic antibiotics for the TVT procedure. Gynecol Surg (in press)

14. Esinler I, Zeyneloglu HB (2004) Routine cystoscopy is not needed in TOT outside-in. Eur Urol 46:675

15. Neuman M (2006) Transvaginal suture placement for bleeding control with the tension-free vaginal tape procedure. Int Urogynecol 17:176-177

16. Liapis A, Bakas P, Creatsas G (2002) Burch colposuspension and tension-free vaginal tape for the management of stress incontinence in women. Eur Urol 41:469-473

17. Ward KL, Hilton P (2004) United Kingdom and Ireland tensionfree vaginal tape Trial group. A prospective multicenter randomized trail of tension-free vaginal tape and colposuspension for primary urodynamic stress incontinence: two-year follow-up. Am J Obstet Gynecol 190:324-331

18. Grise P, Lobel B, Grall J (2003) Les complications du TVT. Prog Urol 13:144-146

19. Cody J, Wyness L, Wallace S et al (2003) Systemic review of the clinical effectiveness and cost-effectiveness of TVT for the treatment of urinary stress incontinence. Health Technol Asssess 7:1-189

20. Costa P, Delmas V (2004) Trans-Obturator-tape procedure "inside out or outside in": current concept and evidence based. Current Opin Urol 14:313-315 